\title{
Biotechnology Research and Development in Academia: providing the foundation for Egypt's Biotechnology spectrum of colors. Sixteenth Annual American University in Cairo Research Conference, American University in Cairo, Cairo, Egypt
}

\author{
Rania Siam
}

\begin{abstract}
Address: Biotechnology Graduate Program, Biology Department and the YJ-Science and Technology Research Center, American University in Cairo, Cairo, Egypt

Email: Rania Siam - rsiam@aucegypt.edu
\end{abstract}

from 2009 American University in Cairo Research Conference

Cairo, Egypt. 5 April 2009

Published: I July 2009

BMC Proceedings 2009, 3(Suppl 3):II

This article is available from: http://www.biomedcentral.com/I753-656I/3/S3/II

(c) 2009 Siam; licensee BioMed Central Ltd.

\begin{abstract}
Biotechnology research and development in Egypt was addressed in the 2009 annual American University in Cairo (AUC) research conference held at the AUC new campus in Cairo, Egypt, that took place on April 5th 2009. The aim of the event was to present examples of ongoing biotechnology research activities in Egypt with focus on agricultural and biomedical biotechnology and to highlight the expansion of academic biotechnology research to industry.
\end{abstract}

\section{Overview}

Biotechnology is a cutting edge interdisciplinary field combining technologies and expertise of personnel in different fields to contribute extensively to pharmaceutics, diagnostics, medicine, agriculture, and the environment. The biotechnology field literally comes in a spectrum of colors red, white/grey [1], green and blue [2]. The conference has discussed several research endeavors in Egypt contributing to the biotechnology field and how such research has direct industrial applications or would direct the expansion of the biotechnology field.

This was addressed by discussing examples of biotechnology research and development in academia; representative participants from (1) the Center of Excellence for Advanced Sciences (CEAS), Genetic Engineering and Biotechnology Research Division (GEBRD), National Research Center (NRC), in Cairo, Egypt, (2) Sinai Univer- sity, in North Sinai, El Arish, El Masaid, Egypt, (3) Naval Medical Research Unit-3, Abbasia, Egypt and the (4) YJScience and Technology Research Center, (5) the Biology Department, and the Biotechnology Graduate Program at the American University in Cairo. Participants gave a general overview of ongoing research activities that would contribute extensively to the biotechnology industry, additionally a few examples on ongoing research and development in biotechnology industries were discussed.

Worldwide biotechnology hotbed communities have contributed to the fact that biotechnology is one of the most renowned applied sciences of the 21st century. In North America several biotechnology hotbeds exist from the southern Biotech Bay and Biotech Beach to the eastern coast Genetown and the northern BioCanada; which not only encompass the biotechnology industry but also the pharmaceutical and medical device industries. The EU 
Biotech is another advanced biotechnology hotbed community and is believed to be a "world leader" in biotechnology and pharmaceutical research and development. AsiaBio is another proven biotechnology hotbed that has successfully competed in the biotechnology field internationally. Egypt is part of the AfriBio biotechnology community and the conference addressed how research and development in academia is contributing to the development of biotechnology in industry [3].

The conference started with an overview of industrial Biotechnology in Egypt, which is considered a hub for scientific knowledge and collaborative research activities in the region. Egypt has dealt with biotechnological needs in several sectors including the biomedical sector by local synthesis of needed biotechnology products. For example in the biomedical field, collaboration with international organizations has allowed the production of recombinant human insulin in several organizations. Additionally, local Egyptian companies have successfully produced other biological products including recombinant human interferon $\alpha-1 b$, erythropoietin $\alpha$ and streptokinase. Additionally, the biomedical and agricultural biotechnology are expanding and the technology permits the exploration of other potential biotechnological products. In the plant biotechnology sector transgenic plants were engineered that are resistant to infestations. In addition several efforts were successfully performed to molecularly engineer plants that are resistant to different stresses.

The first couple of talks discussed research in Trichoderma Ressei as a potential ethanol fuel producer from cellulose biomass. Hamza El-Dorry from the American University In Cairo, discussed a project entitled "Genomic approach for ethanol fuel production from cellulose" [4]. The work of his group addressed evolution of different biochemical pathways for energy production and provided Saccharomyces cerevisiae and Trichoderma Ressei as model systems. They have previously utilized expressed sequence tag analysis and cDNA microarray to investigate the metabolic pathway involved in glucose metabolism [5]. They analyzed the expression of the enzymes involved in glycolysis, tricarbocylic acid cycle and the electron transport chain under high glucose concentration and have revealed distinct discrepancies between these two organisms that have allowed the understanding of the aerobic and anaerobic skews under high glucose concentration in both models used. Similarly, Bishoy Hanna in Dorry's research group at the American University in Cairo and a graduate student in the AUC biotechnology graduate program, presented the identification of potential hexose transporters in Trichoderma reesei, and studied their structure by in-silico analysis of motifs and structure domain [6]. Dorry's group previously analyzed the transcription activity of other glucose transporter genes in T. reesei, and assessed differential expression under altered oxygen and glucose conditions [7]. The group believes that such rigorous study of the biochemical pathways involved in energy production from glucose will allow biotechnology application of this fungus through ethanol production from cellulosic biomass. Mahmoud Sakr, the following speaker also included bioethanol and biofuel production in the future plan of their organization.

Mahmoud Sakr at the Center of Excellence for Advanced Sciences (CEAS) and Genetic Engineering and Biotechnology Division of the National Research Center (NRC), in Cairo, Egypt discussed ongoing research and development that allowed the launching of new local biotechnology products [8]. His division has a broad research entity including plant, animal and microbial research and development. A pilot unit for the application of genetic engineering and biotechnology was also established to help in the scaling up and process development of biotechnology-based products. Examples of their biotechnology diagnostic and research kits products include:

-Peroxidase and urease diagnostic kits

-Triplet PCR for HCV detection kit,

\section{-Plasmid DNA isolation kit}

Dr. Mohei ElDin Soliman, at the vaccine development unit of the National Research Center also discussed efforts in designing and engineering hepatic $\mathrm{C}$ virus vaccines.

From the agricultural biotechnology aspect they also discussed genotyping Egyptian barley resistant to net blotch disease [9], biopesticides and biofertilizers, Virus-free potato seeds, tissue culture plants and transgenic plants and have outlined them as the focus of research and development in their organization and further work is continued to develop plants resistant to stresses and infections. Rose Lines, from the Department of Primary Industries, Victoria, Australia discussed molecular diagnostics tools used in the identification of strawberry viruses in Australia $[10,11]$. The idea was to develop an effective, rapid and less costly process for the indexing of the strawberry nucleus collection in Victoria.

Applications for green (agricultural and horiculture research and development were addressed) and white/ grey (research in biofuel) biotechnology were concluded at this point. The red biotechnology research (biomedical) was continued, as well as a project on blue biotechnology (marine genomic research). Rania Siam addressed ongoing diverse research activities in the Biotechnology Graduate Program, Biology Department and the YJ-Science and Technology Research Center at AUC that are a 
reflection of the diverse research activities at AUC [12]. Siam outlined and discussed the following selected research topics:

-Genetic variations and molecular disease discovery of an isolated community in Egypt.

-Molecular and genomic approach to investigate links between infectious diseases and cancer development.

-Role of cell cycle proteins in maintaining genomic integrity in a eukaryotic model system.

-Structural and functional analysis of diverse strains of influenza genome.

-Metagenomic studies of marine organisms in the Red Sea.

-Comparative metabolic profiling of selected biological systems.

-Development and characterization of novel antibodybased as well as molecular diagnostic tests for detection of tumor biomarkers and infectious diseases.

-Therapeutic and diagnostic applications of nanotechnology.

-Early prediction of tumorogenic changes in cell cycle genes in Hepatitis C.

-Using optical traps to study the mechanical properties of biological polymers.

-Improving durability of biomedical implants through deposition of nanomaterials and nanocomposite thin film using various techniques.

-Fabrication of sensors and MEMS/NEMS for controlling the biological function of the various organs of the body.

These projects are currently being conducted in laboratories and research centers at AUC including but not limited to the YJ- Science and Technology Research Center, the Marine Biology Laboratory at the John Gerhardt Field Station in Al-Gouna and laboratories in several other departments at AUC. Additionally, collaboration with local research institutes as the National Research Center and the US-Naval Medical Research Unit-3 as well as collaboration with several international universities and research institutes permits cutting-edge research activities that are unique and essential for the region. One of the projects vigorously discussed was a metagenomic study of marine organisms in the Red Sea, which is an environmental genomic approach for the study of microbial communities in the Red Sea. The aim of this project is to establish an environmental genomics database for microbial communities residing in unique environments in the Red Sea and screen the database for potential Biotechnological and pharmaceutical products. This project is a collaborative research project with King Abdullah University for Science and Technology, KSA and Woods Hole Oceanographic Institute, Boston, Massachusetts.

The shift to biomedical research and development was apparent with the focus of the remaining presentations on cancer biology and infectious diseases epidemiology. Ashraf Bakkar from the Biochemistry department at Sinai University discussed different mutations in FGFR3 and TP53 revealed by studying 81 bladder cancer tumors [13]. They suggested two distinct pathways in bladder cancer associated with these mutations [13][14]. Additionally, an allele specific PCR (AS-PCR) assay [15] for the detection of such mutations not just in tumor tissues but also in patients' urine represented an exceptional diagnostic tool. Iteration on the importance of such finding not just to understand the mechanism of tumorogenesis but as a diagnostic and prognostic tool in urothelial cell carcinoma (UCC) which could have important implication in both the diagnosis and follow up of UCC patients. Similarly, Mary Boutrous from the Siam group, at the American University in Cairo discussed how the expression and methylation status of the tumor suppressor gene Lats1 in carcinoma could be a potential diagnostic and prognostic marker [16]. She pointed out to previous work in transgenic mice and mammalian cell lines that revealed an overexpression of Lats 1 in selected tumors in mice (Siam et al., unpublished results). Further, investigation revealed that methylation status of the Lats1 promoter region inversely correlate with Lats1 expression and interestingly correlate with different prognostic stages of carcinoma.

Epidemiology of infectious diseases in the region was the focus of the remaining talks that addressed the importance of infectious diseases surveillance in the region for appropriate preventive and treatment strategies. Lamyaa Shaaban a graduate student in the AUC Biotechnology graduate program discussed her project at the US-Naval Medical Research Unit-3 (NAMRU-3) in Abbassia, Cairo, Egypt [17]. The presentation addressed Vibrio cholerae pandemics and outbreaks [18] with emphasize on shift in strains and prevalent serotypes. The study focused on the genotype characterization of different epidemiologic strains of numerous 2007 African outbreaks. Molecular characterization of strains using polymerase chain reaction (PCR), multilocus variable tandem repeat analysis (MLVA), mulitlocus sequence typing (MLST), and DNA sequencing for previously identified virulent genes are in progress. Similarly, Lobna Mourad also a graduate student 
in the Biotechnology graduate program and is conducting her thesis at the US-Naval Medical Research Unit-3 in Abbassia, Cairo, Egypt discussed the project on Extendedspectrum $\beta$-lactamases (ESBLs) [19]. She explained the challenges with the emergence of antimicrobial resistant strains $[20,21]$ and discussed a study on the molecular characterization of ESBL producing bacteria by sequence analysis of $b l a_{\mathrm{CTX}-\mathrm{M}}, b l a_{\mathrm{SHV}}$, and $b l a_{\mathrm{TEM}}$ genes and the establishment of a genotypic map of the ESBL samples using PFGE. The last two speakers from the AUC biotechnology graduate program and NAMRU-3 emphasized the importance of surveillance of infectious diseases in the region for the appropriate preventive measures and effective vaccine and antimicrobial development.

The spectrum of colors in biotechnology was discussed. Blue biotechnology is the focus of the current ongoing project between the American University in Cairo, King Abdullah University for Science and Technology and Woods Hole Oceanographic Institute on an environmental genomics approach to analyze marine microorganisms in the Red Sea for biotechnological and pharmaceutical potentials. Green Biotechnology and novel approaches in transgenic crops has been addressed in more than one talk. Additionally, Red Biotechnology and the genetic engineering technology was a major component of the ongoing projects at Center of Excellence for Advanced Sciences (CEAS) and Genetic Engineering and Biotechnology Division of the National Research Center (NRC), in Cairo, Egypt. The conference was concluded by addressing the importance of academic research and development in providing the platform for the spectrum of colors in biotechnology.

\section{Future conference}

The American University in Cairo annual research conference will be held in 2010. Details on the conference will be posted on the AUC website at http://www.auce gypt.edu

\section{Competing interests}

The author declares that they have no competing interests.

\section{Authors' contributions}

RS wrote the report and organized the involvement and participation of the speakers

\section{Acknowledgements}

The author wishes to thank the AUC organizing committee and the presenters that contributed to its success. In addition, the author wishes to acknowledge Mohammed Khedr for critical reading of the article. Publication cost was provided by the AUC "Coordination of a Conference Grant" to RS.

This article has been published as part of BMC Proceedings Volume 3 Supplement 3, 2009: Egypt's Biotechnology Research and Development in
Academia: providing the foundation for the Biotechnology spectrum of colors. The full contents of the supplement are available at http:// www.biomedcentral.com/ $1753-656 \mid / 3$ ? issue=S3.

\section{References}

I. Frazzetto G: White Biotechnology. EMBO Rep 2003, 4(9):835-7.

2. Chappell J, Grotewold E: Plant biotechnology - predictive, green and quantitative. Curr Opin Biotechnol 2008, I 9(2): 129-30.

3. Siam R: Introduction to the panel on Biotechnology Research and Development in Industry. BMC Proceedings 2009, 3(Suppl 3):Ol.

4. Dorry $\mathrm{H}$ : Elucidation of the metabolic fate of glucose in Trichoderma ressei using EST analysis and cDNA microarray: a step towards metabolic engineering of the regulatory networks for anaerobic metabolism for glucose. BMC Proceedings 2009, 3(Suppl 3):O2.

5. Chambergo FS, Bonaccorsi ED, Ferreira AJ, Ramos AS, Ferreira Júnior JR, Abrahão-Neto J, Farah JP, El-Dorry H: Elucidation of the metabolic fate of glucose in the filamentous fungus Trichoderma reesei using expressed sequence tag (EST) analysis and cDNA microarrays. J Biol Chem 2002, 277( I 6): | 3983-8.

6. Hanna B, Ramos A, Chambergo FS, Mahmoud A, El Dorry H: Hexose Transporters in Trichoderma Resei ; Structure, Function and Regulation. BMC Proceedings 2009, 3(Suppl 3):O3.

7. Ramos AS, Chambergo FS, Bonaccorsi ED, Ferreira AJ, Cella $N$, Gombert AK, Tonso A, El-Dorry $\mathrm{H}$ : Oxygen- and glucosedependent expression of Trhxtl, a putative glucose transporter gene of Trichoderma reesei. Biochemistry 2006, 45(26):8184-92.

8. Sakr MM: Plant Biotechnology at NRC, Egypt: on going Research and Future Plan. BMC Proceedings 2009, 3(Suppl 3): 04 .

9. Saker MM: A biological and molecular characterization of some Egyptian barley genotypes which are resistant to net blotch disease. Cell Mol Biol Lett 2005, I 0(2):265-80.

10. Lines R, Kelly G, Milinkovic M, Rodoni B: Runner Certification and virus elimination in commercial strawberry cultivars in Australia. Acta Hort (ISHS) 2006, 708:253-254.

II. Constable F, Bottcher C, Kelly G, Lines R, Milinkovic M, Persley D, Rodoni B: Molecular diagnostics for the detection of strawberry viruses in Australia. BMC Proceedings 2009, 3(Suppl 3):05.

12. Siam R: Overview of Biotechnology research activities at the Biotechnology graduate program. BMC Proceedings 2009, 3(Suppl 3):O6.

13. Bakkar A: FGFR3 and TP53 mutations in urothelial cell carcinoma: Two molecular pathways and diagnostic value. $B M C$ Proceedings 2009, 3(Suppl 3):O7.

14. Bakkar AA, Quach V, Le Borgne A, Toublanc M, Henin D, Wallerand H, Radvanyi F, Bittard H, Ravery V, Gibod LB, de Medina SG, Chopin DK, Grandchamp B: Sensitive allele-specific PCR assay able to detect FGFR3 mutations in tumors and urine from patients with urothelial cell carcinoma of the bladder. Clin Chem 2005, 5 I (8): I 555-7.

15. Bakkar AA, Wallerand H, Radvanyi F, Lahaye JB, Pissard S, Lecerf L, Kouyoumdjian JC, Abbou CC, Pairon JC, Jaurand MC, Thiery JP, Chopin DK, de Medina SG: FGFR3 and TP53 gene mutations define two distinct pathways in urothelial cell carcinoma of the bladder. Cancer Res 2003, 63(23):8108-12.

16. Boutrous M, Siam R: Lats I differential expression in selected human cancers. BMC Proceedings 2009, 3(Suppl 3):08.

17. Shaban L, Ahmed SF, Materu S, Klena JD: Outbreak investigation: Molecular characterization of Vibrio cholerae isolates from Horn of Africa. BMC Proceedings 2009, 3(Suppl 3):O9.

18. Lee JH, Han KH, Choi SY, Lucas ME, Mondlane C, Ansaruzzaman M, Nair GB, Sack DA, von Seidlein L, Clemens JD, Song M, Chun J, Kim DW: Multilocus sequence typing (MLST) analysis of Vibrio cholerae OI EI Tor isolates from Mozambique that harbour the classical CTX prophage. J Med Microbiol 2006, 55(Pt 2): 165-70.

19. Mourad L, Nicklasson M, Siam R, Pimentel G: Molecular Characterization of Extended-spectrum- $\beta$-lactamases Producing Klebsiella pneumoniae and Escherichia coli from Hospitalized Patients in Oman. BMC Proceedings 2009, 3(Suppl 3):OI0.

20. Perez F, Endimiani A, Hujer KM, Bonomo RA: The continuing challenge of ESBLs. Curr Opin Pharmacol 2007, 7(5):459-69. 
21. Pitout JD, Nordmann P, Laupland KB, Poirel L: Emergence of Enterobacteriaceae producing extended-spectrum betalactamases (ESBLs) in the community. J Antimicrob Chemother 2005, 56(I):52-9.

Publish with Bio Med Central and every scientist can read your work free of charge

"BioMed Central will be the most significant development for disseminating the results of biomedical research in our lifetime." Sir Paul Nurse, Cancer Research UK

Your research papers will be:

- available free of charge to the entire biomedical community

- peer reviewed and published immediately upon acceptance

- cited in PubMed and archived on PubMed Central

- yours - you keep the copyright

Submit your manuscript here:

http://www.biomedcentral.com/info/publishing_adv.asp 